\title{
China's Regulatory Framework for Dynamic and Personalized Pricing in the Digital Economy
}

\author{
Feng WANG ${ }^{1}$ \\ ${ }^{1}$ Doctoral students, East China University of Political Science and Law, Shanghai, China \\ Correspondence: Feng WANG, East China University of Political Science and Law, Shanghai, China.
}

Received: October 4, 2021

Accepted: October 28, 2021

Available online: November 5, 2021

doi:10.11114/ijsss.v10i1.5370

URL: https://doi.org/10.11114/ijsss.v10i1.5370

\begin{abstract}
Under the Chinese legal system, in principle, there is no objection to dynamic and personalized pricing of enterprises. Dynamic pricing does not involve the processing of personal information, and consumers have a higher perception of price fairness, it is seldom concerned by laws and policies. Personalized pricing involves the processing of personal information, and consumers generally feel that the price is unfair and difficult to accept, so it is the focus of legal regulation. Enterprises face three obstacles in implementing personalized pricing. First, in terms of personal information protection, enterprises should abide by the provisions on personal consent and automatic decision-making in the Personal Information Protection Law. Second, in the aspect of anti-monopoly, enterprises should abide by the provisions of the Anti-Monopoly Law, and cannot achieve collusion through algorithms and abuse market dominance to implement differential treatment for trading counterparts. Third, in the protection of consumers' rights and interests, enterprises should respect the Price Law and other laws, and cannot commit price fraud and price discrimination. The current law on dynamic and personalized pricing is not perfect. In the future, we can protect consumers' rights and interests mainly by strengthening enterprises' obligation of providing information.
\end{abstract}

Keywords: dynamic pricing, personalized pricing, price discrimination, price fraud

\section{Introduction}

The COVID-19 epidemic has brought great impact to the global economy, and the world economic situation has become extremely complicated and severe, and the economies of all countries are facing the greatest uncertainty. In this context, in order to promote economic stability and rapid development, China strives to promote the integration of digital economy and real economy, and strives to create new advantages of digital economy. In March 2020, the Central Committee of the Communist Party of China and the State Council issued the "Opinions on Building a Better System and Mechanism of Market-oriented Allocation of Factors", which brought data into the scope of production factors for the first time and proposed to speed up the cultivation of data factor market. On June 29th, 2021, Shenzhen, as a pilot area of data legislation, also passed the Data Regulations of Shenzhen Special Economic Zone, which explored and cultivated the data factor market from five aspects and established the relevant system of fair competition in data. According to the White Paper on China's Digital Economy Development published by China Academy of Information and Communications Technology(CAICT) in 2021, the scale of China's digital economy in 2020 has reached 39.2 trillion yuan, accounting for nearly $40 \%$ of GDP, and its growth rate is more than three times that of GDP. Digital economy has become the key power to stabilize China's economic growth.

In the era of digital economy, data is the core factor of production, basic and strategic resource, and also an important productive force.Digitalization provides more opportunities and possibilities for the development of enterprises, and also brings more challenges, one of which is the pricing of enterprises. Digitalization can make it easier and cheaper for enterprises to collect various data. By using the collected data, enterprises can make the prices of their products or services respond to any changes in market conditions in a timely manner, and even make individual adjustments in real time according to consumers' different willingness to pay. Therefore, the price of products or services in the digital economy will change more frequently than ever before, and the price will become more dynamic and personalized.

The pricing freedom of enterprises is a basic component of the free economic order, and an effective pricing strategy is the key to increase demand, sales and profits. However, the rapidly changing prices, especially those customized for consumers, make consumers feel that prices are unfair. In recent years, more and more consumers and media have 
criticized enterprises for implementing dynamic and personalized pricing, and the Chinese government has promulgated a large number of laws to regulate the pricing behavior of enterprises. However, among the dynamic and personalized pricing implemented by enterprises, there is no consensus on which are legal pricing behaviors and which are illegal pricing behaviors. There are also great controversies in the specific application of the relevant laws regulating enterprise pricing. This greatly restricts enterprises from implementing dynamic and personalized pricing on a large scale, which is not conducive to providing Chinese enterprises with competitiveness in the digital economy. The purpose of this paper is to clarify the differences between dynamic pricing and personalized pricing by using economic and legal theories and methods, and to find out the legal obstacles for enterprises to implement dynamic and personalized pricing under the Chinese legal system, so as to provide guidance for the government and enterprises to better regulate and implement dynamic and personalized pricing.

\section{Definition of Dynamic and Personalized Pricing}

\subsection{Dynamic Pricing}

Dynamic pricing does not have a clear and universally acceptable definition for the general public, and is mostly defined from an economic perspective. Some define it, for example, as a strategy in which prices change over time, with consumers and/or with the environment (Haws \& Bearden, 2016). Some define it as a planned unilateral change in a supplier's pricing criteria at any point in the sales process to respond to changing demand or competitive environments in order to maximize profits (Gnsch et al., 2009) Others define it as an essentially identical product with different prices depending on observable environmental conditions, whereby the price can change over time for all buyers and between buyers at the same point in time (Spann \& Skiera, 2020). Dynamic pricing is a pricing strategy for companies. Unlike fixed prices, where prices remain the same even if demand increases, dynamic pricing is a reflection of the principles of supply and demand in the market economy. By constantly adjusting prices, firms are able to respond to fluctuations in demand in order to achieve increased sales and maximize profits. Therefore, this paper defines dynamic pricing as a pricing strategy in which a firm adjusts the price of a good or service at any time in order to maximize profits, based on changes in current market demand, the competitive environment, and other factors. This definition is a narrow dynamic pricing, i.e., dynamic pricing without individual differentiation, where all consumers pay the same price at the same point in time. Dynamic pricing in a broad sense also includes dynamic pricing with individual differentiation, i.e., personalized dynamic pricing, or personalized pricing, where different consumers pay different prices at the same point in time.

While dynamic pricing is as old as commerce itself, the sale of goods or services at fixed, non-negotiated prices is a relatively new "invention" in human history. The French entrepreneur Aristide Boucicaut is said to have been one of the first to set fixed prices for goods, introducing them in his department store "Le Bon Marché" during the Paris World's Fair in 1855, which avoided time-consuming bargaining for each product (Fezer \& Obergfell., 2016). The price in a fixed price is not fixed either, the price is only fixed for a certain period of time and the price is adjusted less often. Before Aristide Boucicaut, fixed prices were not common, and the price of a good or service was determined by the buyer and seller individually. Nowadays, with the rapid development of digitalization and related technologies, the price of goods or services has returned from fixed prices to dynamic pricing. Today's dynamic pricing prices are adjusted more frequently, and prices can change daily, hourly, or even secondly.

\subsection{Personalized Pricing}

As with dynamic pricing, there is no universally accepted definition of personalized pricing.The UK Office of Fair Trading (OFT) defines personalized pricing as a firm's use of observed, voluntarily provided, inferred or collected information about an individual's behavior or characteristics to set different prices for different consumers (whether individuals or groups) that the firm believes they are willing to pay (2013).The Organization for Economic Cooperation and Development (OECD) defines personalized pricing as the practice of price discrimination against end consumers based on their individual characteristics and behaviors, resulting in prices being set as an incremental function of consumers' willingness to pay (2018).The European Commission defines online personalized pricing, which refers to the use of data collected from individuals' online activities, including their web browsing behavior, to customize the prices of goods and services for users (2018).In this paper, personalized pricing is defined as the use of data collected from different consumers with personal characteristics or behaviors, etc., to offer different prices to different customers for the same goods or services at the same time.

Personalized pricing is price discrimination, which is often used in practice as a substitute for individualized pricing. Price discrimination is when a manufacturer sets different prices, including discounts, for different consumers for the same product or service based on the consumer's characteristics, time or place of purchase, amount of purchase, or other relevant information (Badmaeva \& Hüllmann, 2019).There are three forms of price discrimination. First-degree price discrimination, also known as full price discrimination, is when a firm demands a price according to each consumer's 
different willingness to pay (the highest price the consumer is willing to pay) and the firm gets the entire consumer surplus (the amount of money the consumer is willing to pay minus the amount of money he actually pays). First-degree price discrimination is impossible to achieve, the firm cannot know the willingness to pay of each consumer, and the consumer will not show his willingness to pay to the firm. Second-degree price discrimination is when a firm sells different units of a product at different prices, but each person who buys the same quantity pays the same price. Second-degree price discrimination usually includes consumer self-selection of quantity or quality, such as giving discounts to consumers who buy more quantity, and setting airline tickets as first-class or economy class tickets to be chosen by consumers. Third-degree price discrimination refers to firms granting different prices to different groups of consumers. Third-degree price discrimination is the most common form of price discrimination, such as giving discounts to students or elderly people, and giving low prices to locals in scenic spots.

When firms have limited access to data, they can only implement third-degree price discrimination, i.e., price discrimination for specific groups of consumers. As consumers are described in sufficient detail and market segments continue to be refined, firms can segment consumers' willingness to pay section by section, with the result that individualized prices are offered to customers. Thus, personalized pricing is a relatively refined form of price discrimination, which is essentially segmentation based on three levels of price discrimination, with the ultimate goal of achieving one level of price discrimination. In personalized pricing, group prices play a greater role.

\subsection{Distinguish the Meaning}

Dynamic pricing and personalized pricing are often applied as synonyms, but they do not have the same meaning and it is important to distinguish between them. Dynamic pricing takes into account only the aggregate preferences of consumers, and consumers' individual willingness to pay is not taken into account, while personalized pricing is formed on the basis of consumer-specific criteria in the context of the different willingness to pay of the target group, allowing firms to achieve a more precise predation on consumers. Dynamic pricing, in which companies adjust prices according to changes in demand and supply, etc., is an efficient operation of the price mechanism and does not imply any discrimination against consumers. Personalized pricing is based on digitization and mass collection and analysis of personal data, and prices are tailored to the consumer (Gleixner,2020). As a result, there is a significant difference in legal regulation between dynamic pricing, which tends to receive little attention, and personalized pricing, which is highly controversial.

\section{Influencing Factors, Economic Effects and Barriers to Implementation of Dynamic and Personalized Pricing}

\subsection{Factors Influencing Dynamic and Personalized Pricing}

Companies in the digital economy are facing increasingly new challenges in terms of pricing strategies. Prices for products or services often cannot be set statically, but must be dynamically adjusted over time to suit current conditions. Whereas in the past, companies could set prices by adding a percentage of profit to cost (cost-plus pricing), today they must set prices based on the strategies of their direct competitors (market-oriented pricing) and, in particular, on the demand side (value-based pricing). The ability of a company to adapt its prices to changing circumstances in a very short period of time is also seen as a key success factor (Gnsch et al., 2009).

The main factors affecting dynamic pricing are demand, supply, product and competition. Price sensitivity changes and demand shocks (i.e., changes in demand) are key economic factors that affect dynamic price adjustments, such as gradual price increases for air conditioners due to the arrival of summer and price spikes for masks due to sudden outbreaks of epidemics. Changes in supply factors such as inventory changes, end of sales period, and changes in procurement or manufacturing costs can affect prices, such as lower product prices due to increased inventory. Product characteristics also affect dynamic pricing, especially the shelf life of perishable products and technological innovation, such as the implementation of the national six standards and lead to a significant reduction in the price of national five vehicles. Competitive factors, such as competitors' prices, are important factors affecting dynamic price adjustments (Spann \& Skiera, 2020).

The factors that influence price setting in personalized pricing are mainly the market position of the company and the different willingness to pay of consumers. First, the firm must have a certain degree of market power. Traditional economic theory suggests that if there are multiple firms selling the same product in a competitive market, no firm can sell any quantity at the market price, and no firm is willing to ask any consumer for a lower price, and if a competing firm tries to ask for a higher price, the consumer will switch to another firm's product (Gregory,2012).Second, consumers must have different willingness to pay. Consumers' willingness to pay is usually not directly observable and other variables must be used as indicators of willingness to pay; therefore, sufficient information about consumers is needed to distinguish their segments. Specific distinctions can be made by behavioral, psychological, socio-demographic and geographic criteria. Behavioral criteria include consumer's purchase history, brand loyalty and purchase volume. Psychographic criteria include consumers' lifestyle, attitude toward risk, and expectations of product 
quality. Socio-demographic information includes gender, age, job, education, income, etc. Geographic criteria include province, city, street, etc. (Badmaeva \& Hüllmann, 2019) Companies evaluate consumers' willingness to pay to decide whether to pursue the customer.

In dynamic and personalized pricing, companies often use algorithms for pricing in order to improve the speed and accuracy of designing and adjusting prices. Pricing algorithms have the advantage of "automatically setting prices to maximize profits" by being able to process large amounts of data and react quickly to any changes in market conditions (OECD, 2017).In addition to this, pricing algorithms can reduce the cost of complex pricing and frequent price changes and improve the quality of pricing decisions (Yu, 2020).Companies can use Internet technology to automatically collect competitor price changes in real time and match them to certain merchant prices, or maintain price gaps for certain brands and automatically adjust prices as competitor prices change. Companies can also use more sophisticated algorithms to identify a number of other independent factors that may have an impact on sales volume, such as the type of product display, customer reviews, or different times of day or week. The algorithm can try to determine the importance of each of these influencing factors, predict the sales volume at different prices and adjust the prices.

\subsection{Economic Effects of Dynamic and Personalized Pricing}

\section{1) Impact on social welfare}

Dynamic pricing implies more price volatility, which not only increases price competition among firms, but also leads to increased demand. Thus, dynamic pricing can increase social welfare. With fixed prices, firms with some market power keep prices above marginal costs, thus limiting total output below the socially optimal level. Personalized pricing, on the other hand, has the potential to maximize social welfare. As long as firms can adjust prices to consumers' willingness to pay and profitably provide goods or services to every consumer willing to pay more than the marginal cost of production, they can maximize output and maximize social welfare. At the same time, social welfare may be influenced by the competitive environment. Individualized pricing may either promote or inhibit competition. On the one hand, because firms can predict consumers' willingness to pay, personalized pricing may lead to more intense competition as firms compete with each other for consumers; on the other hand, personalized pricing can help increase firms' market power and increase market concentration, which may harm competition and reduce social welfare (Yu \& Lan, 2021).

\section{2) Impact on consumer welfare}

Dynamic pricing is generally beneficial to consumers, who have wider access to the product or service. For consumers with low willingness to pay, they can choose to purchase when the price is equal to or lower than their willingness to pay, whereas in fixed pricing, this group of consumers may be excluded because the price is higher than their willingness to pay. For consumers with high willingness to pay, they can choose to make a purchase at a low price in order to get more consumer surplus by, for example, searching more deeply or postponing the purchase.

Personalized pricing may benefit or harm consumers, depending largely on the context in which it occurs. First, personalized pricing may result in a surplus shift from consumers with a high willingness to pay to those with a low willingness to pay. Consumers with a high willingness to pay are charged higher prices, depriving them of the consumer surplus that they might have obtained at a fixed price and putting them in a less favorable position. However, this allows firms to profitably offer the same product or service to consumers with low willingness to pay who would otherwise not buy. The benefits to the latter may outweigh the losses to the former, or they may be less than the former (OFT, 2013). Second, personalized pricing does not always guarantee lower prices for consumers with low willingness to pay. Disadvantaged consumers may be discriminated against because of sensitive personal characteristics, or low-income consumers may be charged more for services because they are perceived to be more likely to default on their loans, and it is possible that firms may simply exclude consumers with low willingness to pay.Again, personalized pricing can better provide consumers with customized products or services, but it may also drive companies to lower the quality of their products or services. When firms offer different quality products or services at different prices, one possible strategy to force consumers with a high willingness to pay to choose a high quality, expensive product or service is to reduce the quality of the lower quality offer (Streel et al., 2017).Finally, the impact of personalized pricing on consumer welfare may also depend on the competitive conditions of the market. In monopolistic markets, firms may be better able to use their knowledge of consumer valuations to charge higher prices. In more competitive markets, personalized pricing may lead firms to compete more aggressively for each consumer, which may increase firms' incentives to lower prices (OECD, 2018).As in a duopoly market, total consumer surplus and total social welfare will be maximized once competition is introduced ( $\mathrm{Li}$ et al., 2021).

3) Impact on corporate welfare 
Compared to fixed prices, dynamic and personalized pricing can, at least in theory, better leverage consumers' willingness to pay to increase firm profits, with personalized pricing leading to even higher profits (Spann \& Skiera, 2020).Personalized pricing tends to transfer surplus from the consumer to the firm, and if personalized pricing leads to first-degree price discrimination, the producer receives all the surplus and the consumer's welfare is reduced to zero. However, competitive pressures can limit the ability of firms to extract surplus from economic transactions. Even if firms are able to predict consumers' willingness to pay and offer prices accordingly, consumers are likely to find lower prices for similar products or services offered by other firms, rather than paying prices corresponding to their willingness to pay, and the behavior of some consumers switching sellers is enough to penalize firms. Monopolies can more easily increase profits through individualized pricing, but competing firms do not necessarily benefit from individualized pricing (Streel et al., 2017).In a competitive environment, where firms differ in their ability to obtain data and identify consumers' willingness to pay, asymmetric outcomes can arise, and firms with more data and better algorithms may benefit more than their competitors.

\subsection{Barriers to the Implementation of Dynamic and Personalized Pricing}

\section{1) Consumer's perception of price fairness}

The barrier for companies to implement dynamic and personalized pricing is primarily consumer acceptance of dynamic and personalized pricing, which depends primarily on the consumer's perception of price fairness. Price fairness perception refers to the buyer's judgment of the fairness of the price set by the seller, i.e. how the consumer perceives the price or price change. The dual rights principle suggests that both the seller and the buyer are entitled to a "reasonable" profit and price respectively, i.e., the seller is entitled to a fair profit and the buyer is entitled to a fair price (Vaidyanathan \& Aggarwal, 2003).The more common consumer perception is that prices are the same for everyone and that when one's price is not the same as other consumers' prices, it may be perceived as unfair even if the consumer is profiting from it. The most important reference points for assessing consumer perceptions of price fairness are the prices paid by other buyers and the prices at other times. Haws and Bearden's research suggests that (1) price differences among consumers lead to the greatest perceptions of unfairness and the lowest overall satisfaction, and (2) price changes over very short periods of time are more unfair than changes over longer periods of time (2006).

Prices in dynamic pricing are the same for all consumers at the same time, except that prices change over time. Price adjustments over a short period of time may reduce consumers' perception of price fairness, but consumers are also generally able to recognize that prices can change rapidly due to factors such as supply and demand. Frequent price fluctuations in e-commerce platforms are also well known, with reports that the price of a refrigerator in an e-commerce platform can vary by as much as $\$ 900$ between the highest and lowest within a week, and that there are many items that will be priced almost one day at a time (Beijing Youth Daily,2018).Frequent fluctuations in prices offline are also common, such as finding changes in the price of oil every time you visit a gas station, and daily price changes in supermarkets for items such as dairy and meat. Dynamic pricing increases price transparency, and consumers can easily compare prices and also take advantage of price fluctuations by returning higher-priced items when the price trend is positive and then reordering the item at a lower price. As a result, consumers' perception of price fairness is higher and more acceptable in dynamic pricing. However, companies that mislead consumers into spending money by, for example, raising prices first and then offering discounts, reduce consumers' perception of price fairness and are considered unfair.

Personalized pricing tends to make consumers incapable of estimating prices correctly and is usually perceived as unfair. There are many factors in personalized pricing that affect consumers' perceptions of price fairness. The higher the degree of personalized pricing, the closer to first-degree price discrimination, the lower the consumer's perception of price fairness; personalized pricing based on consumer purchase history is more common, such as giving price discounts to loyal customers, the consumer's perception of price fairness is higher than personalized pricing based on location data alone; the higher the privacy concern, the lower the consumer's perception of price fairness will be (Priester et al., 2020).In addition, the specific implementation of personalized pricing can also highly influence consumers' perception of price fairness, e.g., by giving personalized discounts (e.g., by giving personalized coupons), by involving consumers in the price formation process (e.g., through online auctions), and by combining it with second-degree price discrimination (e.g., through customized products) will enhance consumers' perception of price fairness.By improving consumers' perception of price fairness, the acceptance of personalized pricing can be increased.

2) Goodwill of the enterprise

Another core issue that prevents companies from implementing dynamic and personalized pricing is consumer reaction in the context of perceived price fairness, which can be damaging to a company's image, or at least the risk of being exposed. From an economic perspective, companies can use dynamic and personalized pricing to make more profit, but consumers may perceive this behavior as unfair. Companies fear this phenomenon for fear of consumer retaliation and damage to their goodwill, a cost that can be costly for companies. Consumers' perception of price fairness is key to the sustainability 
of dynamic and personalized pricing, which should allow consumers to benefit from the price they pay, and if they perceive the price to be unfair, the probability of purchase decreases (Richards et al., 2016).This also explains why in industries such as supermarkets and restaurants, companies do not implement dynamic pricing even though there is a significant increase in consumers; in platforms such as e-commerce, companies still do not implement personalized pricing on a large scale even though it is technically perfectly possible to do so, and only focus on a few industries such as travel (flights, hotels, etc.) and taxi.

\section{Legal Regulation of Dynamic and Personalized Pricing}

\subsection{Regulation by the Personal Information Protection Act}

1) Processing of personal data

The use of personal data for pricing is a sensitive issue that raises privacy and data security concerns for consumers. Dynamic pricing does not require the use of personal data for price optimization and is not a critical issue in terms of personal information protection. Personalized pricing, on the other hand, requires the use of personal data and does not fall under the exceptions such as necessary for the conclusion or performance of a contract, and therefore requires the consent of the individual consumer pursuant to Article 1035, paragraph 1, of the Civil Code and Article 13 of the Personal Information Protection Act.

However, the above provisions do not constitute an absolute restriction on personalized pricing. First, data protection laws such as the Civil Code and the Personal Information Protection Act apply only to personal data, and companies using anonymous data or other non-personal data for personalized pricing are not required to comply. The purpose of personalization is usually not to reveal the identity of individuals, and the focus is not necessarily on the desire to collect sensitive personal information or to know whose data is being collected, but on the desire to obtain information about the interests and behavioral characteristics of consumers that will enable them to segment consumers in order to provide more accurate personalized offers to different groups of consumers.Big data applications and the use of algorithms make it possible to process large amounts of data and to link different data to assess and predict consumers' willingness to pay. The processing of anonymous data may not make much sense for companies, as information about pricing is already processed, but by combining large amounts of data, such as location, browser used, operating system, etc., it is possible to eventually establish a reference to the individual consumer (Tillmann \& Vogt, 2018).Second, the distinction between non-personal and personal data is not very clear, and data that is not classified as personal can still be used to identify individual consumers. For example, consumers are segmented through data such as browser and operating system. Finally, even if companies comply with the consumer consent principle, it does not mean anything to consumers. Consumers have no way of knowing what happens to their data and in what form it is used, and even businesses may sometimes be unaware of what happens to the data they collect (Zander-Hayat et al., 2016).Consumers are usually informed about personalization and data collection through privacy statements, but few bother to read or really understand them.

\section{2) Automated decision making}

Another issue of concern is automated decision-making using personal data. Article 22 of the EU General Data Protection Regulation provides that data subjects all have the right not to accept decisions with legal or similarly serious implications for them that are based exclusively on automated processing, including user profiling. The purpose is to protect the human dignity and fundamental rights of data subjects, i.e., that only humans can make decisions with legal effect and that the exercise of fundamental rights should not be subject to algorithmic decision-making (Peter, 2019).

Article 24 of China's Personal Information Protection Law also regulates the use of personal data for automated decision making. Personalized pricing is usually implemented through automated decision-making and falls within the scope of regulation of this article. In terms of content, personalized pricing is, in principle, unobjectionable. Paragraph 1 of this article stipulates that companies should ensure transparency and fair and just results in personalized pricing, and should not apply "unreasonable differential treatment", such as when the price of goods or services differs significantly from the market price. Paragraph 2 stipulates that companies should provide non-personalized options or convenient refusal methods in commercial marketing and information pushing, which in turn indicates that companies can offer personalized prices to consumers. However, according to Article 437 of the Civil Code, price signs in online or offline stores are invitations to offer to consumers, which generally do not have a significant impact on consumers' rights and interests, and consumers do not have the right to refuse personalized pricing.

\subsection{Regulation of the Anti-monopoly Law}

\section{1) Monopoly agreement}

Algorithms have become the most frequently discussed antitrust topic in the digital economy. Not only can algorithms be used to enforce any anticompetitive behavior observable in traditional markets, they may also facilitate the formation 
of new synergistic behaviors that have not been observed before, and may not even have occurred before, known as "algorithmic conspiracy. "Complicity" usually refers to any form of agreement or cooperation between competing firms with the goal of increasing profits to a higher level.While economics studies conspiracy as an outcome of the market, law focuses on the means implemented by competing firms to achieve a conspiratorial outcome. Algorithmic conspiracy by competing firms can achieve the result of excluding and restricting competition by offering the same price to the same consumers, leaving them with no choice. Therefore, prohibiting monopolistic agreements between competing firms through algorithms is the focus of the Antitrust Law's regulation of dynamic and individualized pricing.

Article 13(1) of the Anti-Monopoly Law enumerates the scope of monopoly agreements between operators, and paragraph 2 provides for the principle of monopoly agreements. A monopoly agreement is an agreement, decision or other concerted act to exclude or restrict competition. For agreements or decisions, Article 5, paragraph 2 of the Interim Provisions on Prohibition of Monopoly Agreements (hereinafter referred to as the Interim Provisions) issued by the State Administration of Market Supervision and Administration in 2019 specifies that they can be in written, oral and other forms. Agreements or decisions in the form of written, oral, etc. can be made between competing enterprises to implement common algorithms. Algorithms make conspiracies between competing enterprises more insidious, and conspiracies can occur between competing enterprises without any communication or contact, or even through machine autonomous learning algorithms without any human intervention. Thus, more prevalent in the digital economy are implied conspiracies, i.e., other concerted acts, between conspirators without an explicit agreement or decision.

Article 5(3) of the Provisional Regulation defines other concerted acts, which are acts in which there is substantial coordination between the operators although no explicit agreement or decision has been made. article 5 of the Anti-monopoly Committee of the State Council's Anti-monopoly Guidelines on the Platform Economy (hereinafter referred to as the Platform Anti-monopoly Guidelines) issued in 2021 will "Parallel acts such as price following made by the operators concerned based on their independent intention" are explicitly excluded from other concerted acts. Parallel acts do not fall under the scope of antitrust law and may be the normal result of rational economic behavior of each competing enterprise in the market. If firms unilaterally monitor competitors' prices and raise them at the same time, or if many firms use individualized pricing at the same time, and as their algorithms become more and more similar, there will be identical prices - after all, there is only one price that corresponds to the consumer's willingness to pay. There is an ambiguity between illegal other concerted acts and legal parallel acts, and Article 6 of the Provisional Regulation sets out the factors that should be taken into account when determining other concerted acts, with subparagraph (b) explicitly considering whether there has been meaningful contact or information exchange between operators. In order to regulate monopoly agreements through third parties, Article 8 of China's Platform Antitrust Guidelines provides for in-platform operators to resort to hub-and-spoke agreements with platform operators. Therefore, if there are behaviors such as sharing pricing algorithms or joint use of third-party pricing algorithms among competing enterprises, other synergistic behaviors may be considered to exist even if there is no direct intentional contact or information exchange. It is unclear whether and how conspiracy formed through self-learning algorithms falls within the scope of regulation under antitrust law.

\section{2) Abuse of dominant market position}

Article 17(6) of the Antimonopoly Law prohibits an operator with a dominant market position from abusing its dominant market position and applying differential treatment to the counterparties of transactions under the same conditions without a positive reason. Article 17 of the Platform Antimonopoly Guidelines further clarifies the differential treatment of operators in the platform economy. Differences in price are differential treatment, and therefore, personalized pricing based on the payment ability, consumption preference, and usage habits of transaction counterparties fall within the scope of regulation of this article.

It is not illegal for an enterprise to have a dominant position in the market, but what the antitrust law regulates is the abuse of the dominant position by the enterprise. Personalized pricing constitutes a prohibition of differential treatment under this article if the following four elements are met: (1) the operator has a dominant market position in the relevant market; (2) the operator applies differential treatment in price to the counterparty under the same conditions; (3) the operator's conduct excludes or restricts competition; and (4) the operator has no justifiable reasons for the conduct. An operator with a dominant market position in the relevant market is a prerequisite for antitrust regulation, and an operator without a dominant market position does not fall within the scope of regulation under this article even if it implements personalized pricing. Personalized pricing is implemented directly to consumers or consumer groups, but antitrust laws usually do not consider the impact of personalized pricing on individual consumers, but rather focus on the impact on the entire consumer group or even the entire market (Zhou, 2021).Personalized pricing may promote competition or exclude or restrict competition, but requires a comprehensive judgment based on its effects, but it should be clear that obstruction and unequal treatment of other participants in the market is also a component of competition. For justifiable reasons, Article 17(3) of the Platform Antitrust Guidelines provides in general terms that an enterprise's conduct based 
on the actual needs of the counterparty to the transaction and in accordance with proper trading habits and industry practices, preferential activities for new users within a reasonable period of time, random transactions and other reasons that can justify the conduct are all justifiable reasons. Therefore, from the perspective of antitrust law, personalized pricing is in principle unobjectionable as long as companies with corresponding market power do not abuse their dominant market position.

\subsection{Price Law and Other Laws and Regulations to Regulate}

\section{1) Price fraud}

Article 13(d) of the Price Law provides for price fraud as a price violation. The following three elements must be met to constitute price fraud: (1) the enterprise commits a false or misleading act of price tactics; (2) the consumer is caught in a misunderstanding; and (3) the consumer enters into a transaction with the enterprise as a result of the misunderstanding. Dynamic and personalized pricing are not arbitrary price adjustments. Dynamic pricing is based on a response to changing market conditions, and personalized pricing is a price tailored to the consumer's willingness to pay, and based on pricing freedom and trade secrets, companies are not required to disclose to consumers how prices are calculated. Therefore, in general, dynamic and personalized pricing does not meet the elements of price fraud. However, price fraud can also exist in dynamic and personalized pricing, such as companies offering highly differentiated prices to offline and online customers in order to hide the true price by advertising promotions with false discounts 。

\section{2) Price discrimination}

Article 13(v) of the Price Law provides for price discrimination as a price violation. This subparagraph provides for a price discrimination violation between operators, the purpose of which is to prohibit unfair treatment of operators with the same trading conditions, especially the exclusion of some smaller operators. Personalized pricing is price discrimination, but it is aimed at consumers, not other operators. Therefore, personalized pricing is not the scope of the regulation.

It should be noted that Article 69 of the Data Regulations of Shenzhen Special Economic Zone prohibits market players from using data analysis to impose differential treatment on counterparties with the same trading conditions. This article refers to Article 17 of the Platform Antimonopoly Guidelines, but expands its scope of application. The scope of application of Article 17 of the Platform Antitrust Guidelines is strictly limited, and the complicated procedure for determining whether personalized pricing is an abuse of a dominant market position makes it difficult to impose timely penalties for price violations. Article 69 of the Shenzhen Special Economic Zone Data Regulations, which does not presuppose that an enterprise has a dominant market position, can well regulate price violations, but the provisions of this article are too harsh and fail to fully consider the beneficial effects of personalized pricing on consumer welfare and total social welfare, and strictly limit personalized pricing to specific excluded circumstances with the legal effect of fixed prices. Therefore, the future will have to face the problem of how to limit the scope of application of the article.

\section{3) Misleading by omission}

When choosing between different offers, price is a central factor in a consumer's decision to purchase. Most consumers will assume that they are paying the same price as others for the same product at the same point in time, and do not recognize that prices are individualized. Article 20(3) of the Law on the Protection of Consumer Rights and Interests and the Regulations on the Implementation of Clear Price Indication for Goods and Services only provide that businesses have the obligation to indicate prices clearly, and Article 18(1) of the E-Commerce Law and Article 24(2) of the Law on the Protection of Personal Information only provide that businesses should provide options that are not specific to their personal characteristics. However, Chinese law is silent on whether an enterprise's failure to inform consumers that prices are personalized on the basis of automated decision making constitutes price misrepresentation.

German law tends to regulate personalized pricing through the Unlauterer Wettbewerb-Gesetz (UWG), which, according to Section 5a(2) of the UWG, constitutes an omission of misleading information if the enterprise conceals important information on the basis of which the consumer makes an informed transactional decision and the concealment of this information is likely to lead the consumer to make a transactional decision that he would not otherwise have made. Whether personalized pricing information is material information for the purposes of this article was previously unclear and has become very clear with the enactment of EU Directive 2019/2161 (Gleixner, 2020).Article 45 of EU Directive 2019/2161 states that providing for personalized pricing is permissible per se, but only imposes an obligation on companies to provide information when personalizing pricing so that consumers can take into account the possible risks when making purchasing decisions.In addition, Germany has incorporated the content of this directive into the scope of the obligation to provide information in consumer contracts through Section 312d(1) of the German Bürgerliches Gesetzbuch (BGB), which provides contractual protection for consumers.

Information provision obligations do not necessarily provide very effective protection for consumers, especially as 
personalized pricing becomes more common in the future, but they can at least make consumers aware of the fact that personalized pricing is available so that they are aware of the possible risks when making their decisions.

\section{Conclusion}

In the future digital economy, dynamic and personalized pricing will be further developed, which also brings challenges in terms of personal information protection, market competition maintenance and consumer rights protection. Dynamic pricing and personalized pricing are different in meaning and should be distinguished from each other in terms of legal regulation. Dynamic pricing does not involve the processing of personal data and is not a key issue in terms of personal information protection. Personalized pricing involves the use of personal data for pricing purposes, and the consent of the individual consumer should be obtained in accordance with the provisions of the Personal Information Protection Law, and the implementation of automated decision-making should also ensure transparency and fair and equitable results without unreasonable differential treatment. Conspiracy through algorithms in dynamic and personalized pricing is the focus of regulation under the Antitrust Law. The use of algorithms makes conspiracies between competing firms more concealed and easier to maintain, and the ambiguity between illegal concerted behavior and legal parallel behavior, especially conspiracies formed through self-learning algorithms, poses a challenge to the determination of monopoly agreements. Another focus of the Antimonopoly Law regulation is the abuse of a dominant market position by an enterprise to impose differential treatment on counterparties to transactions under the same conditions. The key to the issue is to determine whether the enterprise has a dominant market position and whether the pricing behavior has the effect of restricting or excluding competition. Digitalization has intensified the information asymmetry between enterprises and consumers, making consumers' rights and interests more vulnerable to damage. The Price Law and other laws mainly regulate price violations in terms of promoting fair trade and protecting consumers' rights and interests. Generally speaking, dynamic and personalized pricing does not constitute price fraud, and price discrimination is limited to between operators; price fraud and price discrimination do not constitute barriers to dynamic and personalized pricing. It is advisable for legislators to exercise restraint with regard to personalized pricing, not to ban it completely because of its possible misconduct, and to carefully weigh the impact on social welfare, consumer welfare and corporate welfare before considering further legal measures to protect the freedom of enterprises to set prices and not to easily deprive consumers of the advantages brought by personalized pricing. In this regard, it is possible to conduct a study that draws on the practices of the European Union and Germany to reinforce the obligation of companies to provide information in the case of personalized pricing.

\section{References}

Badmaeva, T., \& Hüllmann, J. A. (2019). Investigating Personalized Price Discrimination of Textile- ,Electronics- and General Stores in German Online Retail. 14th International Conference on Wirtschaftsinformatik, 1796-1807.

Beijing Youth Daily. (2018). Is the price fluctuation of e-commerce website reasonable? Retrieved from http://epaper.ynet.com/html/2018-04/15/node_1338.htm.

China Academy of Information and Communications Technology. (2021). The White Paper on China's Digital Economy Development. Retrieved from http://www.caict.ac.cn/kxyj/qwfb/bps/202104/P020210424737615413306.pdf

EC. (2018). Consumer market study on online market segmentation through personalised pricing/offers in the European Union. Retrieved from

https://ec.europa.eu/info/sites/info/files/aid_development_cooperation_fundamental_rights/aid_and_development_ by_topic/documents/synthesis_report_online_personalisation_study_final_0.pdf

Fezer, \& Obergfell. (2016).Lauterkeitsrecht:Lauterkeitsrecht:UWG.Rn. 81a.

Gleixner. (2020). Personalisierte Preise im Onlinehandel und Europas "New Deal for Consumers".VuR ,417-421.

Gnsch, J., Klein, R., \& Steinhardt, C. (2009). Dynamic Pricing-State-of-the-Art.Zeitschrift für Betriebswirtschaft, Ergänzungsheft, 3, 1-40.

Gregory, M. (2012). Principles of Microeconomics (6th ed.). South-Wsestern, Cengage Learning.

Haws, K. L., \& Bearden, W. O. (2016). Dynamic Pricing and Consumer Fairness Perceptions. Journal of Consumer Research, 3, 304-311. https://doi.org/10.1086/508435

Li, S. X., \& Wu, Y. F. (2021).Big data, personal information protection and price discrimination - an analysis based on a vertically differentiated duopoly model. Economic Research, 1, 43-57.

OECD. (2017). Algorithms and Collusion: Competition Policy in the Digital Age. Retrieved from http://www.oecd.org/daf/competition/Algorithms-and-colllusion-competition-policy-in-thedigital-age.pdf

OECD. (2018). Personalised Pricing in the Digital Era. Retrieved from 
https://one.oecd.org/document/DAF/COMP(2018)13/en/pdf

OFT. (2013). Personalised Pricing - Increasing Transparency to Improve Trust. Retrieved from http:/www.oft.gov.uk/shared_oft /markets-work/personalised-pricing/oft1489.pdf

People's Court Daily. (2021). "a woman in Zhejiang who used Ctrip to collect unnecessary information to" kill her mature "and applied for refund, one compensation and three support". Retrieved from http://rmfyb.chinacourt.org/paper/html/2021-07/13/node_4.htm

Peter, R. (2019). Dynamische und personalisierte Preise zwischen Vertragsfreiheit und Willkür. Ochs C, Friedewald M, Hess T., Lamla J. (Eds.), (2019). Die Zukunft der Datenökonomie. Medienkulturen im digitalen Zeitalter. Springer VS, Wiesbaden.

Priester, A., Robbert, T., \& Roth, S. (2020). A special price just for you: efects of personalized dynamic pricing on consumer fairness perceptions. Journal of Revenue and Pricing Management, 19, 99-112. https://doi.org/10.1057/s41272-019-00224-3

Richards, T. J., Liaukonyte, J., \& Streletskaya, N. A. (2016). Personalized pricing and price fairness. International Journal of Industrial Organization, 44, 138-153. https://doi.org/10.1016/j.ijindorg.2015.11.004

Spann, M., \& Skiera, B. (2020). Dynamische Preisgestaltung in der digitalisierten Welt. Schmalenbachs Zeitschrift für betriebswirtschaftliche Forschung, 3, 321-342. https://doi.org/10.1007/s41471-020-00095-0

Streel, A. D., Bourreau, M., \& Graef, I. (2017). Big Data and Competition Policy: Market power, personalised pricing and advertising. Centre on Regulation in Europe. https://doi.org/10.2139/ssrn.2920301

Tillmann, \& Vogt. (2018). Personalisierte Preise im Big-Data-Zeitalter.VuR, 447-455.

Vaidyanathan, R., \& Aggarwal, P. (2003). Who Is the Fairest of Them All? An Attributional Approach to Price Fairness Perceptions. Journal of Business Research, 6, 453-463. https://doi.org/10.1016/S0148-2963(01)00231-4

Yu, L., \& Lan, J. H. (2021). Antitrust law regulation of algorithmic personalized pricing: a consumer segmentation-based perspective. Social Science, 1, 77-88.

Yu. L. (2020). Misinterpretation and Identification of the Attributes of Algorithmic Consumer Price Discrimination Antitrust Law. Jurisprudence, 9, 83-99.

Zander-Hayat, R., \& Steffen. (2016). Personalisierte Preise: Eine verbraucherpolitische Einordnung. VuR, 403-410.

Zhou, W. (2021).Anti-monopoly regulation of personalized pricing algorithm in artificial intelligence era. Journal of Wuhan University (Philosophy and Social Sciences Edition), 1, 108-120.

\section{Copyrights}

Copyright for this article is retained by the author(s), with first publication rights granted to the journal.

This is an open-access article distributed under the terms and conditions of the Creative Commons Attribution license which permits unrestricted use, distribution, and reproduction in any medium, provided the original work is properly cited. 